\title{
Abordagens da Educaçáo Especial no Brasil entre Final do Século XX E INício do SÉculo XXI ${ }^{1}$ \\ ApPROACHES OF SPECIAL EDUCATION IN BRAZIL BETWEEN THE END OF THE 20 TH CENTURY and the BeginNing of THE $21 S_{T}$ CENTURY $^{2}$
}

\author{
Mônica de Carvalho Magalhães KASSAR ${ }^{3}$ \\ Andressa Santos REBELO ${ }^{4}$
}

RESUMO: Há um crescente conjunto de pesquisas que se dedicam ao estudo da política da Educação Especial e da educação inclusiva no Brasil e de suas características. A partir do conhecimento dessa literatura, este artigo objetiva analisar possíveis mudanças de perspectivas na política pública de educação brasileira direcionada ao aluno da Educação Especial de 1974 a 2014. Para o desenvolvimento do trabalho, foram consultados documentos e dados oficiais disponibilizados pelo Ministério da Educação brasileiro e pelo Instituto Nacional de Estudos e Pesquisas Educacionais Anísio Teixeira (INEP). Esse material foi analisado com interlocução da literatura sobre Educação Especial/inclusiva e política educacional, sob a perspectiva de que a política educacional é parte do conjunto de políticas sociais que, de modo mais evidente a partir da promulgação da Constituição de 1988, são concebidas e implantadas na tensão entre diferentes forças: das entidades em defesa dos espaços públicos, das instituições não governamentais e de organismos internacionais, dentro de contingências de cada momento histórico e das restriçôes econômicas no período. Conclui-se evidenciando desafios a serem enfrentados, especialmente ao que tange ao direcionamento de recursos públicos e às formas de atendimentos propostas.

PALAVRAS-CHAVE: Política educacional. Educação Especial. Inclusão educacional.

\begin{abstract}
There is a growing body of research devoted to the study of the policy of Special Education and inclusive education in Brazil and its characteristics. From the knowledge of this literature, this paper aims to analyze possible changes in perspectives in the Brazilian education public policy directed at students of Special Education from 1974-2014. For the development of this work, official documents and data provided by the Brazilian Ministry of Education and National Institute of Pedagogical Studies Anísio Teixeira (INEP) were consulted. This material was analyzed through the literature on Special/inclusive Education and education policy, from the perspective that education policy is part of the set of social policies that, more clearly from the promulgation of the 1988 Constitution, are conceived and implanted in the tension between different forces: entities in defense of public spaces, non-governmental institutions and international organizations, within the contingencies of each historical moment and economic constraints in the period. It concludes by highlighting challenges to be faced, especially regarding the targeting of public resources and the forms of assistance proposed.
\end{abstract}

KEYWORDS: Education policy. Special Education. Educational inclusion.

\section{INTRODUÇÃo}

A produção científica brasileira que investiga a política para a escolarização dos alunos da Educação Especial ${ }^{5}$ e suas características tem sido expressiva nos últimos anos (Ferreira \& Bueno, 2011; Baptista \& Pedó, 2013). Como se verá neste artigo, essa produção busca compre-

\footnotetext{
${ }^{1}$ http://dx.doi.org/10.1590/S1413-65382418000400005

${ }^{2}$ Apoio Financeiro: Conselho Nacional de Desenvolvimento Científico e Tecnológico (CNPq).

${ }^{3}$ Doutora em Educação e Professora pela Universidade Federal de Mato Grosso do Sul (UFMS), Corumbá-MS, Brasil. monica. kassar@gmail.com

${ }^{4}$ Doutora em Educação e Professora pela Universidade Federal de Mato Grosso do Sul (UFMS), Corumbá-MS, Brasil. andressarbl@gmail.com

${ }^{5}$ No decorrer dos anos, a categorização da população atendida pela Educação Especial vem mudando. Neste texto, utilizamos as nomenclaturas como empregadas nas fontes consultadas.
} 
ender e desvendar diferentes aspectos desse processo. A partir de questionamentos suscitados pela leitura desses trabalhos, este artigo objetiva analisar possíveis mudanças de perspectivas na política pública de educação brasileira direcionada a essa população entre 1974 e 2014 . No ano de 1974, é elaborado o primeiro levantamento que se tem conhecimento sobre dados de escolaridade do aluno da Educação Especial no Brasil (Ministério da Educação [MEC], 1975a; 1975b). O ano de 2014 refere-se ao fim do primeiro governo de Dilma Rousseff, possibilitando a análise de certos ciclos.

Para o desenvolvimento do trabalho, foram consultados documentos e dados disponibilizados pelo Ministério da Educação brasileiro, por meio do Instituto Nacional de Estudos e Pesquisas Educacionais Anísio Teixeira (INEP). Esse material foi analisado com interlocução da literatura sobre educação especial/inclusiva e política educacional, sob a perspectiva de que a política educacional é parte do conjunto de políticas sociais (Azevedo, 2008) que, de modo mais evidente a partir da promulgação de 1988, são concebidas e implantadas na tensão entre diferentes forças: das entidades em defesa dos espaços públicos, das instituições não governamentais e de organismos internacionais, dentro de contingências de cada momento histórico e das restriçóes econômicas no período (Koerner, 2003).

Relativamente aos dados oficiais, é necessário esclarecer que órgãos da estrutura do Estado coletam dados e produzem estudos estatísticos, reunindo informaçóes sobre um conjunto de unidades de observação. Neste trabalho, recorremos aos levantamentos estatísticos, sinopses estatísticas e resumos técnicos entre 1974 e 2014 e aos microdados obtidos pelo Censo Escolar da Educação Básica (MEC/INEP), entre 2007 e 2014. Advertimos que, no decorrer do período estudado, as formas de coletas de dados empreendidas e as categorias utilizadas pelos órgãos federais foram alterando-se e tornando-se mais complexas, de modo a tentar atender às demandas de cada circunstância histórica e social. Assim, nem todos os dados disponíveis em um período estão em outro, o que impede a obtenção de uma série histórica completa e realização de sua análise integral. Também, é possível haver diferenças de informaçóes em um mesmo ano, a depender da fonte com a qual se trabalha, por exemplo, se diretamente com microdados do Censo Escolar ou com informaçóes geradas na plataforma Data Escola Brasil do INEP. A considerar esses aspectos, mesmo correndo o risco de inadequaçôes, desenvolvemos algumas análises comparativas entre as épocas.

Cabe ainda esclarecer que, embora este artigo apresente dados originais, trata-se de um trabalho que se propóe a olhar uma realidade já estudada pela área, com a intenção de formar um panorama do movimento da escolarização dos alunos da Educação Especial no Brasil entre o final de século XX e início do XXI.

\section{A CRIANÇA “DA EDUCAÇÃO ESPECIAL” APARECE COMO ALUNO NA ESCOLA BRASILEIRA}

O levantamento realizado em 1974 intitula-se "Educação Especial" e é composto de dois volumes. O primeiro apresenta "Dados estatísticos" até aquela data (MEC, 1975a) e o segundo é o "Cadastro Geral dos estabelecimentos do ensino especial” (MEC, 1975b). A obra foi uma realização do Centro Nacional de Educação Especial (CENESP) e do serviço de Estatística da Educação e Cultura (SEEC) e se apresenta como um "trabalho pioneiro em termos de conhecimento e análise da realidade educacional da criança excepcional", que "traça um roteiro informativo completo das instituiçóes públicas e particulares, que formam a rede de serviços 
prestados a educandos excepcionais" (MEC, 1975b, n.p.) e que intenciona assegurar definitivamente a Educação Especial no sistema estatístico do Ministério da Educação (MEC, 1975a).

Segundo esses registros, a Irmandade da Santa Casa de Misericórdia de São Paulo, em atividade desde finais do século XVI, proporcionaria atendimento a pessoas com deficiência física (MEC, 1975b, p. 142). No entanto, como bem adverte Bueno (1991), não é possível saber se nesse espaço institucional realmente ocorria escolaridade a essa população e nem em outros espaços registrados até meados do século XX. Isso se deve a, ao menos, dois motivos: até o final da década de 1980, documentos oficiais registravam o atendimento de reabilitação como parte do processo educacional para uma parcela específica da população (Portaria Interministerial $n^{\circ}$ 186, 1978). Outro aspecto refere-se ao fato de que não há informaçóes se as datas cadastradas se referem ao ano em que o atendimento especializado teve início ou ao de fundação dos estabelecimentos (que podem não ser os mesmos). ${ }^{6}$

Conhecimentos mais precisos sobre a escolarização dessas crianças no país são possíveis pelos esforços de pesquisadores que passam a se dedicar sobre esse tema a partir do final do século XX. Trabalhos como os de Lemos (1981), Jannuzzi (1985) e Bueno (1991), além do mérito da originalidade da temática em que se envolveram, abriram caminhos para que outros pesquisadores pudessem se ater a aspectos mais específicos da história da Educação Especial no país (Müller, 1998; Rafante, 2006; Jannuzzi \& Caiado, 2013), um tema em construção.

Esses trabalhos possibilitam dimensionar o problema de acesso à escola no Brasil até meados do século XX, já que esta era um espaço distante para uma grande parcela da população brasileira e não apenas a pessoas com deficiência. $\mathrm{O}$ processo de industrialização do país e as mudanças na organização urbana daí decorrentes trazem impactos evidentes para a política educacional. Observa-se, no período, a ampliação do número de escolas, alunos e de cobertura educacional (Ribeiro, 1979), especialmente a partir da década de 1970, quando a escolaridade obrigatória passa de quatro (o primário) para oito anos (o $1^{\circ}$ grau), em 1971.

Jannuzzi (2004) evidencia a perspectiva adotada à época, que relaciona diretamente educação e setor produtivo e fundamenta e dirige os olhares para a educação das pessoas com deficiências. A base é a Teoria do Capital Humano presente no dimensionamento da política educacional e demais políticas públicas brasileiras. $\mathrm{O}$ atendimento especializado para alunos com deficiências é entendido como serviço à disposição da população. À época foram dispostas diferentes modalidades: Escola Empresa, Creche, Oficina Protegida, Oficina Pedagógica, Centro Ocupacional, Hospital-dia, Clínica de Orientação, Clínica, Hospital, Centro de Reabilitação, Escola Especial, Ensino Regular. Em 1974, havia ainda registro de matrículas em “outras modalidades” não identificadas (MEC, 1975a).

Cabe relembrar que, na década anterior, a primeira Lei de Diretrizes e Bases da Educação (Lei No 4.024/ 1961) já considerava crianças excepcionais como parte de seu quadro de alunos, indicando o conhecimento no Brasil de mudanças importantes no cenário internacional em relação a essa população. ${ }^{7}$ Como já analisado (Jannuzzi, 1985; Ferreira, 1993), a legislação

\footnotetext{
${ }^{6}$ Entendemos que essas "lacunas" indicam a necessidade de continuidade de pesquisas no campo da história da educação/educação especial.

${ }^{7}$ Referimo-nos às alteraçóes ocorridas inicialmente na Dinamarca em 1959, propostas por Bank-Mikkelsen, e posteriormente, à publicação do conceito de normalização pelo sueco Bengt Nirje. Recuperado de http://www.sagepub.com/upm-data/5901_En-
} 
brasileira previa o encaminhamento de alunos excepcionais à programação clínica e/ou educacional, a partir de um prognóstico construído com base em um diagnóstico psicopedagógico (Portaria Interministerial $\mathrm{N}^{\circ}$ 186, 1978). O registro de espaços como hospital-dia, clínica de orientação, hospital, centro de reabilitação como "educação especial" é indicativo dessa perspectiva terapêutica. Outro aspecto a ser ressaltado na obra publicada em 1975 é que "Ensino Regular" se refere à situação em que o aluno frequenta qualquer tipo de atividade nas escolas "regulares" (ou comuns), seja esse espaço a classe especial, a classe comum com apoio ou a sala de recursos.

Os atendimentos em Educação Especial passaram a estar presentes nas diferentes redes de ensino para atender aos encaminhados para classes especiais, serviços de apoio pedagógico, salas de recursos, entre outros, demanda esta ampliada devido à expansão da escolaridade obrigatória e às decorrências de sua inadequação (Schneider, 1977; Patto, 1990). Nos anos subsequentes, as classes especiais constituíram-se, em grande parte, em espaços de exclusão escolar (Paschoalick, 1981; Ferreira, 1993).

\section{Os ESPAÇOS POSSÍVEIS DA EDUCAÇÃO ESPECIAL}

Na década de 1980, há a continuidade de ampliação da rede de ensino para cumprimento de sua universalização (Núcleo de Estudos de Políticas Públicas [NEPP], 1988). Esse movimento fortalece-se com a promulgação da Constituição Federal de 1988, que estabelece um conjunto de direitos sociais de acesso universal, e, na década de 1990, com os compromissos assumidos pelo país na Conferência de Jontiem em 1990 e com a assinatura da Declaração de Nova Delhi de 1993.

O governo de Fernando Henrique Cardoso (1995 - 2002) inicia após a divulgação da Política Nacional de Educação Especial (Política Nacional de Educação Especial na Perspectiva da Educação Inclusiva, 1994), que especificava as modalidades: atendimento domiciliar, classe comum, classe especial, classe hospitalar, centro integrado de educação especial, escola especial, oficina pedagógica, professor de ensino itinerante, sala de recursos e sala de estimulação precoce para atendimentos educacionais especializados. Com essas modalidades, o quadro de turmas e matrículas no início desse governo foi o seguinte:

\begin{tabular}{|c|c|c|c|c|c|c|}
\hline \multicolumn{7}{|c|}{ Número de turmas por modalidade de atendimento educativo } \\
\hline Total & Sala de recursos & $\begin{array}{c}\text { Oficina } \\
\text { pedagógica }\end{array}$ & $\begin{array}{l}\text { Clas. comum cl } \\
\text { apoio especial. }\end{array}$ & $\begin{array}{l}\text { Classe } \\
\text { especial }\end{array}$ & $\begin{array}{c}\text { Educação } \\
\text { precoce }\end{array}$ & Outros \\
\hline 29.533 & 4.058 & 3.613 & 1.436 & 11.167 & 1.785 & 7.474 \\
\hline$\%$ & 13,74 & 12,24 & 4,86 & 37,81 & 6,05 & 25,30 \\
\hline \multicolumn{7}{|c|}{ Número de alunos matriculados por modalidade de atendimento educativo } \\
\hline Total & Sala de recursos & $\begin{array}{c}\text { Oficina } \\
\text { pedagógica }\end{array}$ & $\begin{array}{l}\text { Clas. comum cl } \\
\text { apoio especial. }\end{array}$ & $\begin{array}{c}\text { Classe } \\
\text { especial }\end{array}$ & $\begin{array}{c}\text { Educaçáo } \\
\text { precoce }\end{array}$ & Outros \\
\hline 291.521 & 43.556 & 38.730 & 13.476 & 106.420 & 15.623 & 73.716 \\
\hline$\%$ & 14,94 & 13,30 & 4,63 & 36,50 & 5,35 & 25,28 \\
\hline
\end{tabular}

Tabela 1. Serviços de Educação Especial no Brasil: Número de turmas e de alunos matriculados (1996)

Fonte: Rebelo (2016), com base em Instituto Nacional de Estudos e Pesquisas Educacionais [INEP] (1998). Obs.: Quando um aluno é atendido em mais de uma modalidade, ele é registrado em cada uma das modalidades.

tries_Beginning_with_B_Albrecht_Rev_I_Proof.pdf e Nirje (1999). 
No total, em 1996, foram registradas 291.521 matrículas de alunos da Educação Especial para uma população geral de 44.584 .650 estudantes da pré-escola e dos atuais Ensino Fundamental e Médio, o que significava aproximadamente 0,65 das matrículas gerais. Em relação aos níveis de ensino, as matrículas estavam divididas em: 78.948 (39,25\%) na Educação Infantil, $118.575(58,95 \%)$ no $1^{\circ}$ grau (atual Ensino Fundamental) e 3.619 (1,80\%) no 2o grau (atual Ensino Médio), sendo o total nessas etapas de 201.142 matrículas $^{8}$ (Rebelo, 2016).

Em 1998, o Governo Federal divulga o alcance de 95,8\% de cobertura de matrículas de crianças entre sete e 17 anos na escolaridade obrigatória (Durham, 1999), superando a meta mínima de 94\% de cobertura a essa população estabelecida no Plano Decenal de Educação (MEC, 1993). O crescimento da rede escolar e a implantação do conjunto das políticas sociais previsto na Constituição de 1988 ocorrem sob uma vertente neoliberal, com focos específicos em açóes de atendimento à pobreza (Sader \& Gentili, 1999). Nesse panorama, o Brasil assume as diretrizes da Conferência Mundial sobre Necessidades Educativas Especiais, em Salamanca, e o Marco de Ação com a necessidade de escolarizar todas as crianças, inclusive aquelas com dificuldades mais severas, e dirige a atenção para as escolas comuns. Das diretrizes dispostas nos documentos de 1994, ressaltamos:

[...] personas con necesidades educativas especiales deben tener acceso a las escuelas ordinarias, que deberán integrarlos en una pedagogía centrada en el niño (p. viii) [...] la escuelas ordinarias proporcionan una educación efectiva a la mayoría de los nińos y mejoran la eficiencia y, en definitiva, la relación costo-eficacia de todo el sistema educativo (p. ix) [...] La puesta en común de los recursos humanos, institucionales, logísticos, materiales y financieros de los distintos servicios ministeriales (educación, salud, bienestar social, trabajo, juventud, etc.), las autoridades territoriales y locales y otras instituciones especializadas es un media eficaz de obtener el máximo provecho. Para combinar los criterios educativos y sociales sobre las prestaciones educativas especiales se requerirán estructuras de eficaces que favorezcan la cooperación de los distintos servicios en el plano nacional y local y que permitan la colaboración entre las autoridades públicas y los organismos asociativos (Organização das Naçóes Unidas para a Educação, a Ciência e a Cultura [UNESCO], 1994, p. 42).

Esses trechos, considerados nas contingências históricas e econômicas no Brasil na década de 1990, possibilitam o entendimento de que o projeto de incorporar todas as crianças na educação é totalmente compatível à universalização do ensino obrigatório já assumida pelo país, ou seja, esse compromisso não acarreta, necessariamente, novas açóes; e, de que, no governo de Fernando Henrique Cardoso, a forma de administraçáo pública implantada (Reforma do Aparelho de Estado) previa o incentivo de acordos e convênios (denominados de parcerias) com instituições privadas sem fins lucrativos (processo de publicização). ${ }^{9}$ Por esse processo, instituiçóes de caráter privado assistencial, consideradas na proposição da política de Educação Especial do regime militar como parte da rede de serviços prestados (MEC, 1975b; Pires, 1974), permanecem com o mesmo estatuto. Ainda, a preocupação com a relação costo-eficacia ou custo-benefício (como utilizada no Brasil) é totalmente coerente à perspectiva de

\footnotetext{
${ }^{8} \mathrm{Na}$ Tabela 1, estão as matrículas na Educação Especial nas etapas Pré-escola, Ensino Fundamental e Médio. Na Tabela 7, estão as matrículas nas diferentes modalidades de atendimento, que é diferente da matrícula nas etapas. $\mathrm{Na}$ Tabela 7 , também "quando um aluno é atendido em mais de uma modalidade, ele é registrado em cada modalidade correspondente", conforme a sinopse consultada. 9 Publicização é a "descentralização para o setor público não-estatal da execução de serviços que não envolvem o exercício do poder de Estado, mas devem ser subsidiados pelo Estado, como é o caso dos serviços de educação, saúde, cultura e pesquisa científica" (Cardoso, 1995, p. 12-13).
} 
contenção e direcionamento de recursos do modelo neoliberal adotado nesse governo (R. T. C. Oliveira, 2003).

Nesse ínterim, há uma mobilização das instituições especializadas, com o protagonismo da Confederação Nacional das Associações de Pais e Amigos dos Excepcionais (APAES), para a elaboração e a implantação de um projeto pedagógico para suas escolas especializadas, a APAE Educadora, de modo a adequarem-se às exigências legais e normativas do período, assumindo a educação escolar como eixo central de suas açóes (Meletti, 2006). Dessa forma, essas instituiçóes são consideradas como instituiçóes educacionais e a população atendida continua na condição de aluno para efeito do Censo Escolar e recebimento de possíveis recursos do Ministério da Educação.

Ao findar essa administração, o governo de Lula (2003 - 2010) recebe o seguinte quadro de estabelecimentos que registram matrículas de alunos da Educação Especial:

\begin{tabular}{lcccc}
\hline Total* $^{*}$ & $\begin{array}{c}\text { Classe } \\
\text { especial }\end{array}$ & $\begin{array}{c}\text { Sala de } \\
\text { recursos }\end{array}$ & $\begin{array}{c}\text { Escolas } \\
\text { especiais }\end{array}$ & $\begin{array}{c}\text { C.C. com alunos } \\
\text { da EE }\end{array}$ \\
\hline 29.451 & 4.386 & 4.662 & 2.409 & 17.994 \\
\hline
\end{tabular}

Tabela 2. Número de estabelecimentos em Educação Especial no Brasil, por modalidade (2002) Fonte: Rebelo (2016).

*Um mesmo estabelecimento poderia apresentar um ou mais tipos de atendimento especializado.

As formas de organização e de exposição de dados pelo Governo Federal, dispostas nas Tabelas 1 e 2, não são as mesmas, já que, em 1996, foi registrada a informação de "turmas por modalidades de atendimento" e, em 2002, de "estabelecimento por modalidade de atendimento". Esse fato, a princípio, impediria uma comparação entre o início e o fim do mandato de Fernando Henrique Cardoso, já que um estabelecimento poderia ter funcionando mais de uma turma de classe especial ou sala de recurso. No entanto, considerando o número de 11.167 turmas de classes especiais, em 1996, e de 4.386 estabelecimentos com classes especiais em funcionamento, em 2002, levantamos a hipótese de que, no período, houve diminuição de espaços públicos para atender a alunos da Educação Especial e essa diminuição refere-se ao fechamento dessas classes em escolas estaduais. Dados que sustentam essa hipótese também estão presentes em Rebelo (2016), quando compara o número de estabelecimentos de Educaçáo Especial entre o início e fim do governo FHC, por dependência administrativa.

\begin{tabular}{cccccccccccc}
\hline ANO & Total & $\begin{array}{c}\text { Fede- } \\
\text { ral }\end{array}$ & $\%$ & Estadual & $\%$ & $\begin{array}{c}\text { Munici- } \\
\text { pal }\end{array}$ & $\%$ & Públ. & $\%$ & $\begin{array}{c}\text { Part./ } \\
\text { privada }\end{array}$ & $\%$ \\
\hline 1996 & 6.313 & 6 & 0,1 & 3.919 & 62,07 & 1.256 & 19,90 & 5.181 & 82,07 & 1.132 & 17,93 \\
2002 & 6.795 & 3 & 0,05 & 2.449 & 36,04 & 2.317 & 34,10 & 4.769 & 70,19 & 2.026 & 29,81 \\
\hline
\end{tabular}

Tabela 3. Número de Estabelecimentos de Educação Especial, por dependência administrativa no Brasil (1996 e 2002)

Fonte: Rebelo (2016).

Obs.: O mesmo estabelecimento pode oferecer mais de um nível/modalidade de ensino. Nas sinopses, "estabelecimentos de Educação Especial” correspondem a instituiçôes com matrículas de alunos com deficiência. 
$\mathrm{Na}$ Tabela 3, podem ser verificadas as alteraçóes detalhadas de número de estabelecimentos, sob os diferentes setores administrativos, no período: a diminuição geral dos estabelecimentos públicos (de 5.181 para 4.769) e o crescimento dos privados (de 1.132 para 2.026). Dentre a diminuição das instituiçóes públicas, excetua-se o crescimento do número das instituiçóes municipais, provavelmente impulsionado pelo processo de municipalização da educação fundamental e por implantação de salas de recursos, já que, na Tabela 2, é possível verificar o possível crescimento do número dessas salas (de 4.058 turmas em estabelecimentos em 1996 para 4.662 estabelecimentos com esse espaço em 2002). Em relação às instituições exclusivamente de Educação Especial, em 2002, havia 2.409 instituições (quarta coluna da Tabela 2), sendo 1.950 de caráter privado (Rebelo, 2016). Das 459 sob a administração pública, 2 eram federais, 186 estaduais e 271 municipais (Rebelo, 2016).

No final desse mandato, não há registros de estabelecimentos, turmas ou matrículas em educação precoce, oficinas pedagógicas ou outro tipo de atendimento especializado. Tais referências indicam o cumprimento da meta de "encolhimento" da ação pública estatal, segundo as prescrições da reforma administrativa do Estado nesse governo. A diminuição dos espaços públicos especializados ocorre a despeito do crescimento do número de matrículas de alunos da Educação Especial em diferentes estabelecimentos educacionais, como poderá ser verificado na Tabela 4: Em 1996, havia 291.521 matrículas desses alunos e, em 2002, esse ciclo encerra-se com 448.601 matrículas. Comparando as 106.420 matrículas em classes especiais, em 1996, com as 78.353 de 2002, é possível verificar a diminuição de registros nessa modalidade, sustentando as análises anteriores e reforçando a hipótese de fechamento das classes especiais. Registra-se, também, a diminuição percentual de matrículas desses alunos em classes comuns, em relação ao total de matrículas de alunos da Educação Especial (de 31,1\% a 24,8\%).

\begin{tabular}{|c|c|c|c|c|c|c|}
\hline \multirow{3}{*}{ Ano } & \multicolumn{4}{|c|}{ Matrículas da Educaçáo Especial } & \multirow{3}{*}{$\begin{array}{c}\begin{array}{c}\text { Matr. Pop. } \\
\text { geral }\end{array} \\
\text { Total (B) }\end{array}$} & \multirow{3}{*}{$\begin{array}{c}\% \\
\text { (A: B) }\end{array}$} \\
\hline & Classes comuns & Classes especiais & Escolas exclusivas & \multirow{2}{*}{$\begin{array}{l}\text { Total matr. } \\
\text { alunos da EE } \\
\text { (A) }\end{array}$} & & \\
\hline & $\mathbf{N}$ & $\mathbf{N}$ & $\mathbf{N}$ & & & \\
\hline 1996 & $90.379^{*}$ & 106.420 & $94.722^{* *}$ & 291.521 & 44.584 .650 & 0,65 \\
\hline 2002 & 110.704 & 78.353 & 259.544 & 448.601 & 54.716 .609 & 0,81 \\
\hline
\end{tabular}

Tabela 4. Distribuição do número de matrículas de alunos da Educação Especial, por modalidade, e a relação ao número de matrículas da população em geral. Brasil, 1996 e 2002 Governo FHC

Fonte: Elaboração própria com base nas Sinopses Estatísticas do Censo Escolar MEC/INEP.

* Matrículas em classes comuns estão somadas a outros tipos de atendimento, como classe comum + sala de recursos.

** Nos dados referentes ao ano de 1996, os números de matrículas em "classes especiais" e "escolas especiais" não estão desagregados. Dessa forma, chegamos ao total de matrículas em escolas especiais, subtraindo do total de matrículas, os valores de matrículas em Classes Comuns e Classes Especiais.

Outro aspecto ainda chama atenção. Trata-se do aumento de matrículas em escolas especiais, das prováveis $94.722^{10}$ matrículas, em 1996, para 259.544, em 2002. Uma hipótese

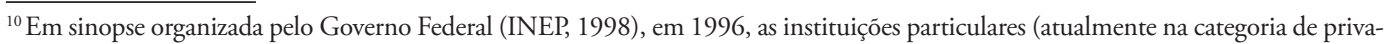
das) tinham um total de 137.517 matrículas em todas as suas modalidades (classe comum, especial, recursos, etc.). Esse total serve de parâmetro para acreditarmos que o número de 94.722 matrículas na modalidade escola especial esteja próximo à realidade nesse ano. 
possível para essa alteração é que a falta de registro das outras formas de atendimento (atenção precoce, oficinas pedagógicas, etc.) pode significar de fato o encerramento desses espaços, que pode ter impulsionado a procura por escolas especiais.

Em 2003, inicia-se o governo Lula e, com ele, a implantação do Programa de formação por multiplicadores para educadores - Educação inclusiva: direito à diversidade. Na sequência, um conjunto de outras açóes foi implementado com o foco central de garantir a matrícula e a frequência de todos os alunos na escola. Grande parte desses programas iniciou suas açóes em 2007, último ano em que o número de matrículas de alunos da Educação Especial foi maior em espaços considerados exclusivos no Brasil. A partir de 2008, o número de matrículas em classes comuns passa a superar os outros espaços.

O Programa Educação inclusiva: direito à diversidade é reconhecido pelo governo posterior (de Dilma Rousseff) como o marco inicial da educação inclusiva no país, que possibilitou "a construção de uma nova política de educação especial que enfrenta o desafio de se constituir, de fato, como uma modalidade transversal desde a educação infantil à educação superior" (MEC, 2016, p. 9).

Em 2003, os registros sobre os atendimentos especializados já estavam reduzidos a matrículas em classes e escolas especiais, salas de recursos e em salas comuns. No fim desse governo, em 2010, o quadro de estabelecimentos que atendem a alunos da Educação Especial é o seguinte:

\begin{tabular}{ccccc}
\hline Total & Classe especial & Sala de recursos & Escolas especiais & $\begin{array}{c}\text { Classes comuns com } \\
\text { alunos EE }\end{array}$ \\
\hline 114.467 & 2.919 & 24.299 & 2.159 & 85.090 \\
\hline
\end{tabular}

Tabela 5. Número de estabelecimentos com registro de Educação Especial no Brasil, por tipo de estabelecimento (2010)

Fonte: Rebelo (2016).

Os números no final do mandato do governo Lula indicam claramente a posição tomada de sua política educacional: a continuidade da diminuição de estabelecimentos do tipo classe especial (de 4.386, em 2002, para 2.919, em 2010), o aumento significativo das salas de recursos (de 4.662 para 24.244) e dos estabelecimentos de educação comum com alunos da Educação Especial (de 17.994 para 85.090). O fato "novo" é a diminuição das escolas especiais (de 2.409 para 2.159). A diretriz dessa política revela-se também nas matrículas durante esse período: das 110.704 matrículas em classes comuns, em 2002, passa-se a 484.332; em 2010, das 78.353 matrículas em classes especiais, vai-se para 46.255; das 259.544 em escolas especiais, em 2002, têm-se 172.016 matrículas, em 2010. Com esses registros, o governo Lula conclui seu mandato considerando a política de educação inclusiva brasileira como bem-sucedida.

O governo de Dilma Rousseff (2011 - 2014) inicia suas açóes com o quadro da Educação Especial definido dentro do que é chamado de perspectiva da educação inclusiva. Em seu mandato, são aprovados decretos e leis que articulam programas já em funcionamento e outros são criados, de modo a instituir uma estrutura de sustentação às açóes já em execução e assegurar legalmente a continuidade da política iniciada em 2003: Em 2011, é aprovado o 
decreto No 7.612, que Institui o Plano Nacional dos Direitos da Pessoa com Deficiência (Plano Viver sem Limite); em 2012, a Lei No 12.764, que institui a Política Nacional de Proteção dos Direitos da Pessoa com Transtorno do Espectro Autista; e, em 2015, a Lei Brasileira de Inclusão da Pessoa com Deficiência (Estatuto da Pessoa com Deficiência), Lei No 13.146. Em 2014, tem-se o seguinte quadro da Educação Especial:

\begin{tabular}{|c|c|c|c|c|c|c|c|c|c|}
\hline \multicolumn{10}{|c|}{ Estabelecimentos com Educaçáo Especial } \\
\hline Ano & \multicolumn{2}{|c|}{ Classes comuns } & \multicolumn{2}{|c|}{ Sala de recursos } & \multicolumn{3}{|c|}{ Classes especiais } & Escolas exclusivas & $\begin{array}{c}\text { Total mat. gerais Ed. } \\
\text { Básica }\end{array}$ \\
\hline 2014 & \multicolumn{2}{|c|}{103.473} & \multicolumn{2}{|c|}{$68.642^{*}$} & \multicolumn{3}{|c|}{1.803} & 2.024 & 175.942 \\
\hline \multirow{3}{*}{ Ano } & \multicolumn{7}{|c|}{ Matrículas da Educação Especial } & Matrícula da & \\
\hline & \multicolumn{2}{|c|}{ Classes comuns } & \multicolumn{2}{|c|}{$\begin{array}{c}\text { Classes espe- } \\
\text { ciais }\end{array}$} & \multicolumn{2}{|c|}{ Escolas exclusivas } & \multirow{2}{*}{ Total (A) } & pulaçáo em geral & \\
\hline & $\%$ & $\mathrm{~N}$ & $\%$ & $\mathrm{~N}$ & $\%$ & $\mathrm{~N}$ & & Total (B) & $(\mathrm{A}: \mathrm{B})$ \\
\hline 2014 & $78,8 \%$ & 698.768 & $3,0 \%$ & 27.004 & $18,2 \%$ & 161.043 & 886.815 & 49.771 .371 & 1,78 \\
\hline
\end{tabular}

Tabela 6. Distribuição do número de estabelecimentos e de matrículas de alunos da Educação Especial e a relação ao número de matrículas da população em geral na Educação Básica (Ministério da Educação, 2014)

Fonte: Elaboraçáo própria com base na Sinopse Estatística da Educaçáo Básica MEC/INEP e microdados do Censo Escolar.

* Aqui é um caso em que, na Plataforma Data Escola Brasil, para o ano de 2014, obtém-se o número de apenas 24.252 escolas com salas de recursos em funcionamento.

\section{A EDUCAÇÁo ESPECIAL NOS Últimos 40 anos}

$\mathrm{Na}$ proposição de olhar os últimos 40 anos de Educação Especial, podemos desenvolver análises entre os diferentes períodos. Uma categoria a ser comparada é a modalidade de atendimento, que possibilita que sejam verificadas as formas de atendimento em funcionamento no período.

\begin{tabular}{c|c|c|c|c|c|c|c|c|c}
\hline Ano & $\begin{array}{c}\text { Ed. pre- } \\
\text { coce }\end{array}$ & $\begin{array}{c}\text { Classe } \\
\text { especial }\end{array}$ & $\begin{array}{c}\text { Sala de } \\
\text { Recursos }\end{array}$ & Of. Ped. & $\begin{array}{c}\text { Atend. } \\
\text { Itinerante }\end{array}$ & Outras & $\begin{array}{c}\text { Escola } \\
\text { Empresa }\end{array}$ & $\begin{array}{c}\text { Escola } \\
\text { Especial }\end{array}$ & $\begin{array}{c}\text { C.C. alunos } \\
\text { EE }\end{array}$ \\
1974 & $*$ & 1.448 & 92 & 118 & 187 & 191 & 3 & 630 & 441 \\
1988 & $*$ & 3.864 & 1.096 & 746 & 437 & 474 & 39 & 1.041 & 480 \\
$1996^{* *}$ & 1.785 & 11.167 & 4.058 & 3.613 & - & 7.474 & - & $*$ & 1.436 \\
2002 & - & 4.386 & 4.662 & - & - & - & - & 2.409 & 17.994 \\
2010 & - & 2.919 & 24.299 & - & - & - & - & 2.159 & 85.090 \\
2014 & - & 1.803 & 68.642 & - & - & - & - & 2.024 & 103.473 \\
\hline
\end{tabular}

Tabela 7. Distribuição do número de estabelecimentos com alunos da Educação Especial, por modalidade. Brasil (1974 - 2014)

Fonte: Elaboração própria com base nas Sinopses Estatísticas da Educação Especial e Educação Básica.

* Indica a existência de estabelecimentos pela existência de dados de matrículas, mas nấo foram encontrados dados de números de estabelecimentos dessas modalidades.

** $\mathrm{O}$ ano de 1996 registrou o número de turmas e não de estabelecimentos, e cada estabelecimento poderia ter mais que uma turma. 
A Tabela 7 mostra que, até o início do governo de Fernando Henrique Cardoso, se registrava um crescimento contínuo de diferentes modalidades de estabelecimentos com matrículas de Educação Especial. A partir do final desse governo, há o crescimento de números de salas de recursos e de classes comuns com matrículas de Educação Especial e a diminuição de classes e escolas especiais e o desaparecimento de registro de outros tipos de estabelecimento. Essas informaçóes evidenciam que os rumos adotados, explicitamente a partir de 2003, já estavam implícitos na política anterior (1995-2002).

Outra possibilidade é dividir os estabelecimentos por responsabilidade administrativa: se pública ou privada e se pública, se federal, estadual ou municipal. Nesse caso, a atenção recai para o investimento de recursos para a Educação Especial.

\begin{tabular}{ccccc}
\hline Ano & Federal & Estadual & Municipal & Privada/Particular \\
\hline 1974 & 12 & 1654 & 115 & 581 \\
1988 & 52 & 4112 & 511 & 1058 \\
1996 & 6 & 3919 & 1256 & 1132 \\
2002 & 3 & 2449 & 2317 & 2026 \\
2010 & 152 & 21141 & 53398 & 12899 \\
2014 & 339 & 24119 & 64557 & 16578 \\
\hline
\end{tabular}

Tabela 8. Educação Especial - Número de estabelecimentos, por dependência administrativa Brasil (1974 - 1988 - 1996 - 2002 - 2010 - 2014)

Fonte: Elaboraçáo própria com base nas Sinopses Estatísticas da Educaçáo Especial e Educaçáo Básica. Obs.: As sinopses não consideraram estabelecimentos com salas de recursos.

Relativamente à divisão por administração dos estabelecimentos, chama atenção o movimento entre os números de instituiçóes públicas e privadas (ou particulares, como eram denominadas até 1988). Dentre as públicas, é evidente a diminuição de instituiçóes sob as administrações federais e estaduais do período que vai da promulgação da Constituição Federal, em 1988, ao término da gestão de Fernando Henrique Cardoso (2002). Nesse período, sobem os números das instituiçóes educativas municipais e privadas (particulares), respondendo, como apontado anteriormente, aos processos de municipalizaçáo e de publicizaçáo. Nas gestóes seguintes, o número de estabelecimentos volta a subir sob todas as formas administrativas, período que corresponde à intensificação de matrículas de alunos da Educação Especial nas escolas comuns, independentemente do crescimento das instituiçóes privadas que recebem alunos da Educação Especial. O crescimento do número de estabelecimentos sob as administraçóes federal, estadual e municipal indica a volta de investimento no setor público, que havia diminuído entre 1988 e 2002.

Em relação às instituiçóes privadas, é interessante notar que o número de escolas especiais caírem (Tabela 7) e o número de estabelecimentos privados aumentarem (Tabela 8) podem ser indicativos de aumento de frequência de alunos da Educaçáo Especial em escolas regulares (/comuns) privadas (/particulares).

Há diferentes possibilidades de olhar e analisar o conjunto de informações disponíveis sobre as açóes que resultam hoje na política de educação inclusiva no Brasil. Uma das formas é a apresentada, em 2016, pela Secretaria de Educação Continuada, Alfabetização, Diversidade e 
Inclusão (SECADI) em um relatório denominado Consolidação da inclusão escolar no Brasil 2003 - 2016 (MEC, 2016), que avalia as açóes da educação inclusiva desde 2003 e esclarece seu ponto de vista frente à política de inclusão. Nele, é atribuído à Política Nacional de Educação Especial na Perspectiva da Educaçáo Inclusiva o papel de orientar Estados, Distrito Federal e Municípios para a transformação dos sistemas educacionais em sistemas educacionais inclusivos (MEC, 2016). O relatório também expóe o conjunto de documentos legais que subsidiam hoje essa política. $\mathrm{Na}$ perspectiva adotada pelo Governo Federal, entende-se que a política de educação inclusiva se sustenta em um novo paradigma: o paradigma da inclusáo. Na sequência, os programas estão elencados, acompanhados de números que expressam, segundo o Governo Federal, seu sucesso e consolidação. Sem desconsiderar os inegáveis esforços das diferentes gestóes para a escolarização dos brasileiros, especialmente dos alunos da Educação Especial, e o registro de experiências positivas nas escolas (Gomes \& Nunes, 2014; Silva, Martinez, \& Santos, 2012), entendemos que há outros aspectos que devem ser observados para a avaliação de nossa política educacional, e a academia tem contribuído significativamente apontando desafios a serem considerados.

O Programa Educação Inclusiva: direito à Diversidade foi objeto de inúmeros trabalhos, que o acompanharam durante anos (M. V. M. Oliveira, 2007; Leodoro, 2008; Caiado \& Laplane, 2009). Esses estudos mostram as características e os limites da proposta: as formaçóes foram rápidas e pontuais, não houve continuidade das equipes envolvidas em diversos municípios, alguns municípios-polo tinham um número excessivo de municípios de abrangência sob sua responsabilidade, não havia recursos humanos ou materiais suficientes para a realização de qualquer tipo de acompanhamento. Ressalta-se que, ainda que seja registrado o alcance do Programa a 5.428 municípios de abrangência (MEC, 2016), os estudos denunciam que, para caracterização de um município atendido, bastava haver a participação de um representante da localidade em uma das capacitaçóes, sem o acompanhamento posterior das açóes daí decorrentes.

O Programa de implantação de sala de recursos multifuncionais, carro chefe do atendimento educacional especializado no Brasil, apresenta o número de $93 \%$ de municípios alcançados (MEC, 2016). Apesar de sua capilaridade, o relatório divulgado em 2016 omite a informação de que nem 50\% dos alunos da Educação Especial, matriculados no ensino comum, têm acesso às salas de recursos multifuncionais (Rebelo 2016). Outros trabalhos atestam a existência de uma polarização entre sala de recursos e sala comum, com o atendimento especializado se restringindo às salas de recursos (Melo, 2008; Jordão, 2013), sem se notar alteraçóes na configuração da sala comum. Em alguns casos, os professores não utilizam a tecnologia assistiva disponível, por desconhecê-la (Emer, 2011). Ainda, as atividades na sala de recursos não vêm mobilizando cognitivamente os alunos (Arnal, 2007; Araruna, 2013), devido ao uso de metodologias insuficientes, além de outros limites importantes (Mendes \& Cia, 2017).

Outros trabalhos levantam possíveis problemas na identificação dos alunos da Educação Especial (Meletti \& Bueno, 2011; Almeida \& Orlando, 2015; Almeida, 2016), assim como a complexidade do diagnóstico nessa área (Bridi, 2011; Valentim \& Oliveira, 2013) e dos encaminhamentos (Gonzalez, 2013). Lembramos que a categoria de deficiência mental/ intelectual é a que tem maior frequência desde o início dos registros: 63,3\% do total de alunos "excepcionais" atendidos (MEC, 1975a), 71,6\% do total de matrículas de alunos com deficiência na Educação Básica em 1981, 68,3\% em 1987, 66\% em 1988, 59,7\% em 1996 e 56,6\% em 1997 (INEP, 1998). Pelos problemas históricos apontados pela literatura especializada em 
relação aos encaminhamentos para as antigas classes especiais para deficiência mental, levantamos a hipótese de que o problema da identificação e o encaminhamento equivocado voltam a ocorrer. Essa circunstância marca a Educação Especial brasileira e é alvo de continuadas críticas (Bueno, 1991; Kassar, 1994). Esse aspecto leva a outro desafio que é a qualidade da escolarização oferecida e, dentro desse aspecto, ressaltam-se a inadequação de abordagens pedagógicas (Pletsch, 2009; Pedroso, 2014), a consequente concentração de matrículas nos anos iniciais do Ensino Fundamental (Meletti, 2013; Françozo, 2014; Almeida \& Orlando, 2015) e os problemas relativos à formação dos educadores (Michels, 2011; Milanesi, 2012; Garcia, 2013; Rios, 2014).

Relativamente à acessibilidade, as escolas brasileiras ainda não têm suas estruturas adequadas (Corrêa \& Manzini, 2012; Capellini \& Lopes, 2013) e a contemplação da instituição com recursos do Programa Escola Acessível para obras não é garantia de acessibilidade arquitetônica, pois há problemas como: inadequação das obras, desrespeito aos padróes técnicos estabelecidos; falta de manutenção posterior dos espaços e até uso inadequado dos espaços para outros fins (Silva Filho, 2017).

\section{ConsideraÇóEs finAIS}

Algumas questóes permanecem nessas quatro décadas da política educacional para alunos da Educação Especial no Brasil: Em qual espaço deve estar o aluno? Em espaços especiais ou espaços comuns? Essa escolha de fato refere-se a uma opção entre segregação e inclusão? Para onde os recursos públicos devem ser direcionados? Devem continuar subsidiando instituições privadas de Educação Especial ou devem ser direcionados à melhoria dos serviços públicos existentes? Correndo o risco de simplificar, é possível perceber respostas diferentes a essas questôes em cada momento. O recorte histórico apresentado intencionalmente na década de 1970 possibilita retomar processos que vêm sendo construídos, como a perspectiva de cumprimento de um direito social e, especificamente, a responsabilidade pública da escolaridade e do atendimento especializado aos alunos da escola brasileira. Com as marcas político-ideológicas de cada tempo, a proposição da Educação Especial parece sempre ter sido garantir um direito social, e esse aspecto está registrado na materialização de espaços públicos diferenciados.

Dos anos de 1970 ao final da década de 1980, sob o foco na utilidade da Educação Especial para o aluno e para o próprio país, há a implantação de espaços públicos e acordos com instituiçôes privadas para garantir o que se chamou de "rede de serviços prestados a educandos excepcionais" (MEC, 1975b, n.p.). O governo de Fernando Henrique Cardoso (1995-2002) destacou o direito à escolarizaçáo e, para os alunos da Educação Especial (à época alunos com necessidades educacionais especiais, como no Relatório Warnock, de 1978), esse processo poderia ser realizado em qualquer espaço considerado educacional (escolas ou classes especiais ou comuns). O conjunto de instituiçóes privadas foi visto como parte da rede de atendimento a essa população e os recursos públicos deveriam subsidiar essa parceria e, sob a óptica do encolhimento dos serviços educacionais e da valorização do setor público não-estatal, os espaços públicos diminuem em sua totalidade, passando de 5.181 no início desse governo a 4.769 estabelecimentos com registros em Educação Especial em 2002. Para atender ao crescimento da matrícula dessa população, verifica-se o aumento de estabelecimentos privados de 1.132 para 2026. 
No governo Lula, a ênfase volta-se à frequência na classe comum, com a possibilidade de atendimento especializado complementar das necessidades educacionais. Há aumento de estabelecimentos públicos, especialmente de salas de recursos e de classes comuns com registro de Educação Especial. Os anos de 2007 e 2008 são marcantes para a política implantada, pois são aprovados Programas que conduzem o direcionamento à matrícula na classe comum (Programa Sala de Recursos Multifuncionais, BPC na escola e Programa Escola Acessível), é divulgado o documento da Política Nacional de Educação Especial na Perspectiva da Educação Inclusiva e ocorre o ponto de inflexão das matrículas entre espaços "exclusivos" (classes ou escolas especiais) e espaços "inclusivos" (salas de aulas comuns). Ressalta-se que, mesmo com a política de valorização da sala de aula comum para escolaridade dos alunos da Educação Especial, há a manutenção dos dispositivos de financiamento público das instituiçóes privadas de Educação Especial.

O governo Dilma (2011-2014) dá continuidade à estrutura organizada na gestão anterior, mas a Educação Especial passa a ser reforçada na perspectiva do respeito à diversidade, inclusive com o encerramento das atividades da Secretaria de Educação Especial.

O princípio de que a inclusão se fundamenta na frequência de todas as crianças na escola comum foi adotado no governo Lula e, na gestáo de Dilma, fortaleceu-se a ideia de que outra forma de atenção que não ocorresse em salas comuns seria vista como segregação e de desrespeito aos Direitos Humanos, discurso este presente em documentos orientadores. Ressalta-se, no entanto, que, mesmo com a disseminação dessa perspectiva, a convivência anteriormente explícita entre espaços exclusivos e as salas comuns mantém-se com a continuidade de financiamento das instituiçóes especializadas privado-assistenciais com recursos públicos. A divulgação do relatório de 2016 externa o entendimento de que a rede educacional brasileira é uma rede de educação inclusiva. Nele, há a assunção de que ocorreu uma mudança de paradigma na política educacional brasileira: de uma Política Nacional de Educação Especial, de 1994, alicerçada no "paradigma integracionista, fundamentado no princípio da normalização, com foco no modelo clínico de deficiência” (MEC, 2016, p. 7) para uma política de inclusão.

O documento de 2016 apresenta a inclusão como uma posição de vanguarda e inovação frente ao que se possuía anteriormente (integração/tradição). Garcia (2017), retomando as análises de Jannuzzi (2004) em trabalho que passou a ser referência de muitos pesquisadores sobre as tendências da Educação Especial, chama atenção para o fato de que o que vem se apresentando como "inovador" carrega, em seu íntimo, uma concepção conservadora de educação e não transformadora, apesar de seu discurso como um "novo paradigma”. Uma das evidências é justamente o modelo de atendimento educacional especializado empreendido que, muitas vezes, mantém a perspectiva clínica e pontual.

A considerar os caminhos da construção da Educação Especial neste país, concluímos observando que movimentos de manutenção de estruturas anteriores convivem com possibilidades de superação e constituição de novas perspectivas. Para enfrentar os inúmeros desafios que a educação nos apresenta, entendemos que é necessário ter coragem para fazer opçóes em relaçáo ao destino dos recursos públicos, assim como para pensar e propor formas diferenciadas de abordagens e espaços educacionais. Nesse sentido, preocupa-nos a posição expressa no relatório de 2016, que classifica formas de atenção educacional como atendimento domiciliar, classes hospitalares, o ensino itinerante e estimulação essencial como manutenção de uma "es- 
trutura paralela e substitutiva da educação especial” (MEC, 2016, p. 7) e algo a ser superado. Como alerta a própria Declaração de Salamanca, educação especializada envolve altos custos (UNESCO, 1994) e os estudos desenvolvidos no Brasil e a existência de diferentes modalidades de atendimento em curso em países europeus (World Health Organization [WHO], 2011) indicam que propostas educacionais adequadas podem demandar, em muitos casos, grandes esforços e não apenas pequenas adaptaçóes.

\section{REFERÊNCIAS}

Almeida, D. L., \& Orlando, R. M. (2015). Inclusão e matrícula de alunos com deficiência nas escolas estaduais: Análise em um município paulista. Comunicaçōes, 22(3), 239-254.

Almeida, T. F. (2016). Análise dos indicadores e políticas de inclusão escolar na baixada fluminense (Dissertação de Mestrado). Programa de Pós-Graduação em Educação, Contextos Contemporâneos e Demandas Populares, Universidade Federal Rural do Rio de Janeiro, Seropédica, RJ, Brasil.

Araruna, M. R. (2013). Dos desafios às possibilidades: A prática pedagógica do professor do atendimento educacional especializado com o aluno que apresenta deficiência intelectual (Dissertação de Mestrado). Universidade Federal do Ceará, Fortaleza, CE, Brasil.

Arnal, L. S. P. (2007). Educação escolar inclusiva: A prática pedagógica nas salas de recursos (Dissertação de Mestrado). Universidade Estadual de Maringá, Maringá, PR, Brasil.

Azevedo, J. M. L. (2008). A Educaçâo como Política Pública. Campinas: Autores Associados.

Baptista, C. R., \& Pedó P. M. (2013). Atendimento educacional especializado: Uma análise sobre pesquisa em universidades brasileiras (2002-2012). Cadernos de Pesquisa em Educação, 19(37), 25-38.

Bridi, F. R. S. (2011). Processos de identificaçâo e diagnóstico: Os alunos com deficiência mental no contexto do atendimento educacional especializado (Tese de Doutorado). Universidade Federal do Rio Grande do Sul, Porto Alegre, RS, Brasil.

Bueno, J. G. S. (1991). Educação especial brasileira: A integração/segregação do aluno diferente (Tese de Doutorado). Pontifícia Universidade Católica de São Paulo, São Paulo, SP, Brasil.

Caiado, K. R., \& Laplane, A. L. (2009). Programa Educação Inclusiva: direito à diversidade: Uma análise a partir da visão de gestores de um município-polo. Educação e Pesquisa, 35(2), 303-315.

Capellini, V. L. M. F., \& Lopes, J. F. (2013, setembro). Educação inclusiva em questâo: Análise da interação e infraestrutura de uma escola. Anais do Congresso Nacional de Educação, Curitiba, PR, Brasil, 11. Recuperado em 25 de fevereiro de 2018 de http://educere.bruc.com.br/ANAIS2013/pdf/9584_6372.pdf

Cardoso, F. H. (1995). Plano Diretor da Reforma do Aparelho do Estado. Brasília: Câmara da Reforma do Estado.

Corrêa, P. M., \& Manzini, E. J. (2012). Um estudo sobre as condiçóes de acessibilidade em pré-escolas. Revista Brasileira de Educação Especial, 18(2), 213-230.

Durham, E. R. (1999). A educação no governo de Fernando Henrique Cardoso (Dossiê FHC $1^{\circ}$ governo). Tempo Social: Revista de Sociologia da USP, 2(11), 231-254.

Emer, S. O. (2011). Inclusão escolar: Formação docente para o uso das TICs aplicada como Tecnologia Assistiva na sala de recurso multifuncional e a sala de aula (Dissertação de Mestrado). Programa de Pós-Graduação em Educação, Universidade Federal do Rio Grande do Sul, Porto Alegre, RS, Brasil. 
Ferreira, J. R. (1993). A exclusão da diferença. Piracicaba: Unimep.

Ferreira, J. R., Bueno, J. G. S. (2011). Os 20 anos do GT Educação Especial. Revista Brasileira de Educação Especial, 17(Ed. Espec.), 143-170.

Françozo, R. V. (2014). O Atendimento Educacional Especializado para estudantes com deficiência visual em Corumbá-MS e Ladário-MS (Dissertação de Mestrado). Universidade Federal de Mato Grosso do Sul, Corumbá, MS, Brasil.

Garcia, R. M. C. (2017). Disputas conservadoras na política de Educação Especial na perspectiva inclusiva. In R. M. C. Garcia (Org.), Políticas de educaçâo especial no Brasil no início do século XXI (259 p.). Florianópolis: Núcleo de Publicaçôes do CED - NUP.

Garcia, R. M. C. (2013). Política de educação especial na perspectiva inclusiva e a formação docente no Brasil. Revista Brasileira de Educação, 18(52), 101-119.

Gomes, R. C., \& Nunes, D. R. P. (2014). Interaçóes comunicativas entre uma professora e um aluno com autismo na escola comum: Uma proposta de intervenção. Educação e Pesquisa, 40(1), 143-161.

Gonzalez, R. K. (2013). Educação especial e processos de encaminhamento para sala de recursos: Relação de gênero e cor/raça (Tese de Doutorado). Universidade de São Paulo, São Paulo, SP, Brasil.

Instituto Nacional de Estudos e Pesquisas Educacionais (1998). Sinopse Estatística da Educação Básica: Censo Escolar 1998. Brasília: INEP. Recuperado em 5 de julho de 2018 de http://download.inep. gov.br/download/censo/1998/basica/censo-miolo-98.pdf

Jannuzzi, G. S. M. (2004). Algumas concepçôes de educação do deficiente. Revista Brasileira de Ciências do Esporte, 25(3), 9-25.

Jannuzzi, G. S. M. (1985). História da Educação do Deficiente Mental no Brasil (Tese de Doutorado). Universidade Estadual de Campinas, Campinas, SP, Brasil.

Jannuzzi, G. S. M., \& Caiado, K. R. M. (2013). APAE: 1954-2011: Algumas reflexóes. Campinas: Autores Associados.

Jordão, S. G. F. (2013). Política de inclusão escolar na ótica de professores das salas de recursos multifuncionais (Dissertação de Mestrado). Universidade do Vale do Itajaí, Itajaí, SC, Brasil.

Kassar, M. C. M. (1994). Diagnosticar a deficiência mental: Sim ou não? Revista Brasileira de Educação Especial, 2, 85-92. Recuperado em 5 de julho de 2018 de http://www.abpee.net/ homepageabpee04_06/artigos_em_pdf/revista2numero1pdf/r2_art08.pdf

Koerner, A. (2003). O papel dos direitos humanos na política democrática: Uma análise preliminar. RBCS, 18(53).

Lemos, E. R. (1981). A educação de excepcionais: Evolução histórica e desenvolvimento no Brasil (Tese de Livre Docência). Universidade Federal Fluminense, Niterói, RJ, Brasil.

Leodoro, J. (2008). A inclusão escolar e a formação continuada: O programa Educação Inclusiva: Direito a diversidade (Dissertação de Mestrado). Universidade de São Paulo, São Paulo, SP, Brasil.

Meletti, S. M. F. (2006). Educação Escolar da pessoa com deficiência mental em instituiçóes especiais: Da política à instituição concreta (Tese de Doutorado). Universidade de São Paulo, São Paulo, SP, Brasil.

Meletti, S. M. F. (2013). A escolarização de alunos com deficiência intelectual: Análise dos indicadores educacionais brasileiros. In S. M. F. Meletti, \& J. G. S. Bueno (Orgs.), Políticas Públicas Escolarização de alunos com Deficiência e a Pesquisa Educacional (1a ed.). Araraquara: Junqueira \& Martin. 
Meletti, S. M. F., \& Bueno, J. G. B. (2011). O impacto das políticas públicas de escolarização de alunos com deficiência: Uma análise dos indicadores sociais no Brasil. Linhas Críticas, 17(33), 367-383.

Melo, H. A. (2008). O acesso curricular para alunos com deficiência intelectual na rede regular de ensino: A prática pedagógica na sala de recursos como eixo para análise (Dissertação de Mestrado). Universidade Federal do Maranhão, São Luís, MA, Brasil.

Mendes, E. G., \& Cia, F. (2017). Aspectos da organização e funcionamento do atendimento educacional especializado: Um estudo em larga escala. Educação em revista, 33, 1-18.

Michels, M. H. (2011). O que há de novo na formação de professores para a Educação Especial? Revista de Educação Especial, 24(40), 219-232.

Milanesi, J. B. (2012). Organização e funcionamento da sala de recursos multifuncionais em um município paulista (Dissertação de Mestrado). Universidade Federal de São Carlos, São Carlos, SP, Brasil.

Ministério da Educação (1975a). Educação Especial: Dados Estatísticos - 1974 (v.1). Brasília: Apex.

Ministério da Educação (1975b). Educação Especial: Cadastro Geral dos estabelecimentos do ensino especial (v. 2). Brasília: Apex.

Ministério da Educação (1993). Plano Decenal de Educação para Todos (1993-2003). Brasília, DF: MEC.

Ministério da Educação (2014). Censo Escolar da Educação Básica 2014: Sinopse Estatística da Educação Básica MEC/INEP e Microdados do Censo Escolar. Brasília: MEC.

Ministério da Educação (2016). A consolidação da inclusão escolar no Brasil 2003 a 2016. Brasília: MEC.

Müller, T. M. P. (1998). A primeira escola especial para creanças anormaes no distrito federal: $O$ Pavilhão Bourneville do Hospicio Nacional de Alienados (1903-1920): uma leitura foucaultiana (Dissertação de Mestrado). Faculdade de Educação, Universidade Estadual do Rio de Janeiro, Rio de Janeiro, RJ, Brasil.

Núcleo de Estudos de Políticas Públicas (1988). Brasil 1986: Relatório sobre a situação social do país. Campinas: NEPP.

Nirje, B. (1999). How I came to formulate the Normalization principle. In R. J. Flynn, \& R. A. Lemay (Eds.), A Quarter-Century of Normalization and Social Role Valorization: Evolution and Impact. Otawa: University of Ottawa Press.

Oliveira, R. T. C. (2003). Estado brasileiro e o neoliberalismo. In E. Senna (Org.), Trabalho, educação e política pública. Campo Grande: UFMS.

Oliveira, M. V. M. (2007). Ogoverno Lula (2003-2005) e o Programa Educação Inclusiva: Direito à diversidade: Um passeio pelas politicas públicas para a educação especial. Anais do $1^{\circ}$ Encontro de Políticas Públicas e Inclusão Social, Direitos Sociais e Enfrentamento da Pobreza, Fortaleza, Ceará, Brasil.

Paschoalick, W. (1981). Análise do processo de encaminhamento de crianças das classes especiais para deficientes mentais, desenvolvido nas escolas de $1^{\circ}$ grau da delegacia de ensino de Marília (Dissertação de Mestrado). Pontifícia Universidade Católica, São Paulo, SP, Brasil.

Patto, M. H. S. (1990). A produção do fracasso escolar. São Paulo: Queiroz.

Pedroso, C. C. A. (2014). O ensino de alunos com deficiência na escola comum: Análise das aulas, das concepçóes dos professores e da parceria com os serviços de educação especial: Didática e Prática de Ensino na relação com a Escola (v.1). Fortaleza: EdUECE.

Pires, N. (1974). Educação Especial em foco. Rio de Janeiro: Centro Brasileiro de Pesquisas Educacionais. 
Pletsch, M. D. (2009). Repensando a inclusão escolar de pessoas com deficiência mental: Diretrizes politicas, currículo e práticas pedagógicas (Tese de Doutorado). Universidade Estadual do Rio de Janeiro, Rio de Janeiro, RJ, Brasil.

Política Nacional de Educação Especial na Perspectiva da Educação Inclusiva (1994). Recuperado em 5 de julho de 2018 de http://portal.mec.gov.br/index.php?option=com_ docman\&view=download \&alias=16690-politica-nacional-de-educacao-especial-na-perspectivada-educacao-inclusiva-05122014\&Itemid $=30192$

Portaria Interministerial $n^{\circ} 186$, de 10 de março de 1978. Recuperado em 5 de julho de 2018 de http://www. fazenda.gov.br/acesso-a-informacao/institucional/legislacao/portarias-interministeriais/2007/ portaria-186

Rafante, H. C. (2006). Helena Antipoffe o ensino na capital mineira: A Fazenda do Rosário e a educação pelo trabalho dos meninos "excepcionais" de 1940 a 1948 (Dissertação de Mestrado). Programa de Pós-Graduação em Educação, Universidade Federal de São Carlos, São Carlos, SP, Brasil.

Rebelo, A. S. (2016). A educação especial no Brasil: Indicadores educacionais de atendimento especializado (1973-2014) (Tese de Doutorado). Universidade Federal de Mato Grosso do Sul, Campo Grande, MS, Brasil.

Ribeiro, M. L. S. (1979). História da educação brasileira: A organização escolar (2a ed.). São Paulo: Cortez $\&$ Moraes.

Rios, G. A. (2014). Imagens de si e da sala de recursos multifuncionais em blogs de professores especializados (Dissertação de Mestrado). Universidade Federal de São Carlos, São Carlos, SP, Brasil.

Sader, E., \& Gentili, P. (Orgs.) (1999). Pós-neoliberalismo II: Que Estado para que democracia? (4ª ed.). Petrópolis: Vozes.

Schneider, D. (1977). Alunos excepcionais: Um estudo de caso de desvio. In G. Velho (Org.), Desvio e divergência: Uma critica da patologia social (2a ed.). Rio de Janeiro: Zahar.

Silva Filho, D. M. (2017). Acessibilidade: Uma análise da existência de barreiras à inclusão de alunos com deficiência/NEE na rede municipal de ensino de Corumbá, MS (Dissertação de Mestrado). Universidade Federal de Mato Grosso do Sul, Corumbá, MS, Brasil.

Silva, D. B. R., Martinez, C. M. S., \& Santos, J. L. F. (2012). Participação de crianças com paralisia cerebral nos ambientes da escola. Revista Brasileira de Educação Especial, 18(1), 33-52.

Organização das Naçóes Unidas para a Educação, a Ciência e a Cultura (1994). Declaración de Salamanca y marco de acción para las necesidades educativas especiales. Salamanca: UNESCO.

Valentim, F. O. D., \& Oliveira, A. A. S. (2013). Avaliação da aprendizagem e deficiência intelectual na perspectiva de professores do ensino comum. Revista Diálogo em Educação, Curitiba, 13(40), 851-871.

World Health Organization (2011). World report on disability 2011. Geneva: WHO.

Recebido em: 03/03/2018

Reformulado em: 16/05/2018

Aceito em: 15/06/2018 
KASSAR, M.C.M. \&; REBELO, A.S. 